\title{
COMMENT
}

\section{Connecting ecological and physical time-series: the potential role of changing seasonality}

\author{
D. J. Beare*, E. McKenzie \\ Department of Statistics and Modelling Science, University of Strathclyde, Glasgow G1 1XH, Scotland, UK
}

There are many ecological time-series available to the marine scientific community and it is essential that the patterns they exhibit be investigated and understood. To achieve this it is usually necessary to connect such series to others, e.g. fish abundance to sea-surface temperature, wind stress or food availability. Regression models are popular for analysing such information and can be useful in separating and assessing the relative influences of various effects on a given series. However, in such contexts, serial correlation will often render the statistics derived from such models difficult to interpret-and we feel that this fact is generally under-rated. From the literature available, there is ample evidence of scientific mechanisms between pairs of time-series being supported mainly by the value of statistics such as correlation coefficients. Unfortunately, however, where data are observational, not derived from designed experiments and serially correlated, such statistical tests can be of limited use in deducing scientific mechanisms

Surprisingly, the classical technique of decomposing time-series into separate long-term trend, seasonal, cyclic and noise components is rarely attempted (cf. Broekhuizen \& McKenzie 1995), and, even when information is available at high temporal resolutions, annual averages are often used as summaries (e.g. Fromentin \& Planque 1996, Hirst \& Batten 1998). This obliterates any interesting seasonal structure in the time-series which may be useful in aiding ultimate scientific interpretation.

The purpose of this comment is to promulgate the idea that seasonal structure, omnipresent in environmental data (e.g. Beare et al. 1998), might actually be helpful in explaining mechanism between pairs, or even groups, of time-series where changes in the seasonal structure occur simultaneousiy. The point is illustrated with a dramatic example involving the North

\footnotetext{
•E-mail: douglas@stams.strath.ac.uk
}

Atlantic Oscillation (NAO) index, which is strongly related to the meteorology of the whole North Atlantic region (Hurrel 1995, 1996) and the abundance of Stage 5 and 6 Calanus finmarchicus in the northern North Sea where a change in seasonal structure occurred in 2 series in the same year (1967). Other profound changes in the ecology of the North Atlantic and North Sea have also been noted in that period. In the north-west Atlantic on the Georges Bank, for example, the haddock population crashed in 1967 (see Hayes \& Buxton 1992) but at the same time exploded to the south and east in the North Sea, together with stocks of cod and whiting during a well-documented period known as the 'gadoid outburst'. Also at that time, herring catches fell in the seas around Britain and were replaced by mackerel, which became the new focus of the pelagic fisheries of the northern European nations (Gunderson 1993).

Here, we analyse the NAO and the abundance of Stage 5 and 6 Calanus finmarchicus in the north-western quadrant $\left(57^{\circ}\right.$ to $61^{\circ} \mathrm{N}, 4^{\circ} \mathrm{W}$ to $\left.0^{\circ}\right)$ of the North Sea (Fig. 1). We use the NAO index of Jones et al. (1997) which was constructed using mean-sea-level-pressure data from Reykjavik and Gibraltar and is freely available at the following website: http://www.cru.uea.ac.uk. Jones' NAO data are available as monthly aggregated values and extend from July 1821 to the near present. NAO indices are usually interpreted by examining the long-term trend associated with the winter months. The exclusive use of only this part of the year is justified on the basis of its higher signal to noise ratio. The presence of a long-term trend in the winter NAO, however, indicates that there is a changing seasonal structure within this index. The time-series data for Stage 5 and 6 C. finmarchicus are Continuous Plankton Recorder data (Warner \& Hays 1994).

Both the NAO index (1958 to 1996) and Calanus finmarchicus data (1958 to 1996) were analysed using standard time-series decomposition techniques (e.g. Broekhuizen \& McKenzie 1995) which separate the 


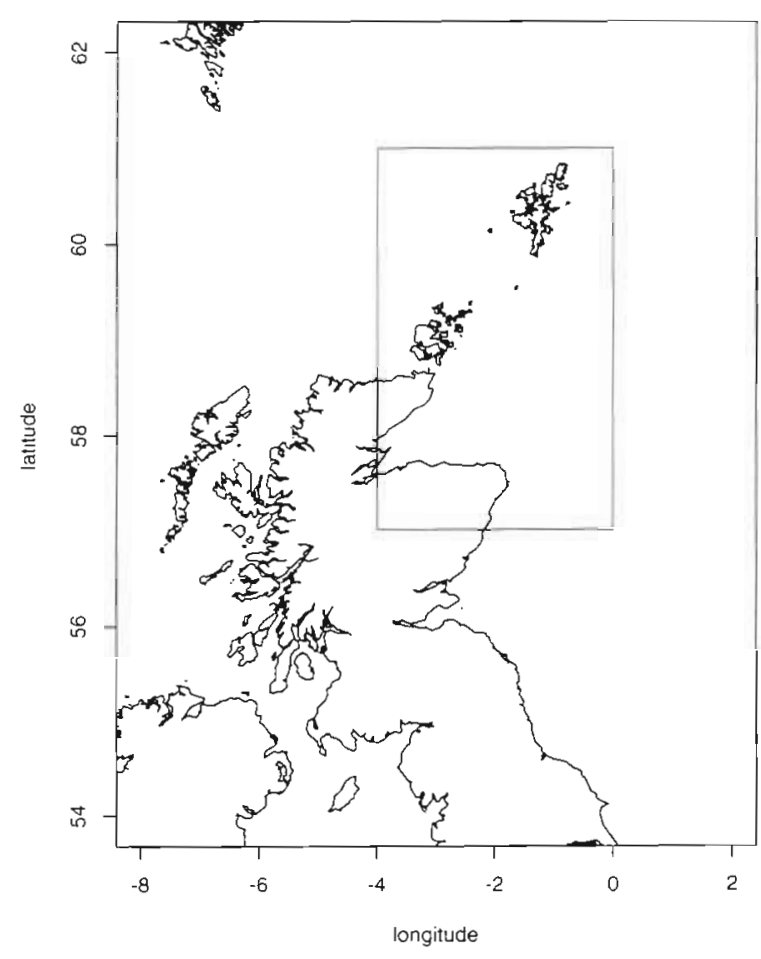

Fig. 1. Location of the Continuous Plankton Recorder data used, defined by the box north-east of Scotland

long-term trend and seasonal structure and allow them to be modelled independently. In this analysis we allowed the seasonal structure to change over time, modelling the changes as smooth trends for each month. Finally, the estimated long-term and seasonal trends were combined to give a 'noise-free' or smoothed estimate of the underlying signals in each series. These are displayed in Fig. 2. The variable-span smoothing algorithm used (supsmu) is available with the S-plus statistical software package. It automatically and objectively selects the degree of smoothness used in the non-parametric fit by cross-validation (Friedman 1984).

The signals observed, admittedly weak for the NAO, are genuine features of the data (see Beare et al. 1998) and are sufficiently robust that they are easily captured using other procedures. Jones et al. (1997) also reported falling spring and summer NAO indices from these data using a different smoothing filter. The magnitude of the fall in abundance of Calanus finmarchicus in the northern North Sea in the late 1960s has been noted before, but not fully appreciated. The failure to recognize the significance of such falls in abundance was due to averaging the data over long time periods such as years.

The most striking features of both series occurred in the same year, 1967. In the smoothed Calanus finmarchicus series (Fig. 2A) population densities were relatively high between 1958 and 1965 but they collapsed in 1967 to a much lower level from which they have not recovered. Associated with this collapse is a change in the form of the bimodal seasonal cycle (Beare et al. 1998). The earleer high abundances were associated with a dominant spring peak whereas, after the collapse, the autumn peak dominated until the mid-1980s.

There are 2 obvious features in the smoothed NAO index series (Fig. 2B). The first of these is that the longterm trend, constant for $35 \mathrm{yr}$, fell dramatically from 1994 to 1996 . The second feature is a dramatic change in the amplitude of the seasonal cycle, high in the late 1950 s, falling to a minimum in the late 1960 s and then increasing steadily into the early 1990s. More importantly, however, is that the form of the seasonal cycle is strikingly different during these 2 periods, before and after the late $1960 \mathrm{~s}$. In the earlier period, April is the annual maximum and is initially high and positive, later falling to around zero (NB see also Jones et al. 1997). After the late 1960s, April is negative and continues to fall, representing the annual minimum until the early 1980s. Similarly, the winter months December to March (on which the winter NAO index is based) are small and negative or close to zero until the late 1960s. After about 1970 the growing amplitude is emphasised by its 3 largest and fastest growing values, January, February and March.

It is our contention that this dramatic change in the seasonal pattern of the NAO index reflects a major contribution to the sudden collapse in Calanus finmarchicus abundances. At present a convincing explanatory mechanism to account for all of the relative details between the 2 series is elusive and clearly more information is required. It is possible that the similarities between the 2 series may be coincidental. Observations such as these, however, are made so rarely from environmental time-series data, and have such potential for deducing scientific mechanisms, that the relationship cannot easily be dismissed.

The life-cycle of Calanus finmarchicus involves a period of hibernation (Backhaus et al. 1994, Hirche 1996) known as diapause that occurs during autumn and winter in deep water $(>600 \mathrm{~m})$. Diapause does not take place within the northern North Sea itself, but on its margins beyond the edge of the continental shelf. The most important (Heath et al. 1998) overwintering location for C. finmarchicus, as far as the northern North Sea is concerned, is the Faroe-Shetland Channel (Fig. 1) where dense accumulations of the copepod are found in cold, southerly flowing Norwegian Sea Deep Water (NSDW) during winter. In early spring, the copepods awake from their diapause condition and begin to ascend to the surface waters where they feed, mate and reproduce. The stimulus that triggers the 
emergence in spring is poorly understood but is evident in this area around the start of April every year. A consequence of this vertical migration en masse is that during April there are high densities of $C$. finmarchicus present in the surface waters to the west and north-west of the Fair Isle current region. Since these copepods are at the mercy of the prevailing water currents, substantial colonisation of the Fair Isle area is probably only possible in the presence of the appropriate physical conditions. These are somehow reflected in the changing April NAO index. Spring and summer NAO indices are considered by some meteorologists to be unimportant because the signal to noise ratios are lower (Hurrel \& VanLoon 1997) than those observed for the winter months. In the context of temperate zone ecology, however, a small signal from an important physical variable such as the NAO occurring at a key moment in the life-cycle of an annual or semi-annual organism may play a crucial role in that organism's survival.

Acknowledgements. This work was funded by the European Union project, TASC (Trans-Atlantic Study of Calanus finmarchicus) as part of the MAST-III programme (contract no. MAS3-CT95-0039).

\section{LITERATURE CITED}

Backhaus JO, Harms IH, Krause M, Heath MR (1994) An hypothesis concerning the space-time succession of Calanus finmarchicus in the northern North Sea. ICES J Mar Sci 51:169-180

Beare DJ, McKenzie E, Speirs DC (1998) The unstable seasonality of Calanus finmarchicus in the Fair Isle current. J Mar Biol Assoc UK 78:1377-1380

Broekhuizen N, McKenzie E (1995) Patterns of abundance for Calanus and smaller copepods in the North Sea: time series decomposition of two CPR data sets. Mar Ecol Prog Ser 118:103-120

Friedman JH (1984) A variable span smoother. Tech Rep No. 5. Laboratory for Computational Statistics, Dept of Statistics, Stanford Univ, CA

Fromentin JM, Planque B (1996) Calanus and environment in the eastern North Atlantic. II. Influence of the North Atlantic Oscillation on C. finmarchicus and C. helgolandicus. Mar Ecol Prog Ser 134:111-118

Gunderson DR (1993) Surveys of fisheries resources. John Wiley \& Sons, Chichester

Hayes DB, Buxton N (1992) Assessment of the Georges Bank haddock stock. Northeast Regional Stock Assessment Workshops, Res Doc SAW13/1, CRD-92-02. Northeast Fisheries Science Center, Woods Hole, MA

Heath MR, Backhaus JO, Richardson K, McKenzie E, Slagstad D, Gallego A, Madden H, Mardaljevic J, Hainbucher D. Schacht A, Jonasdottir S, Beare DJ, Dunn J, Hay $S$ (1998) Climate fluctuations and the abundance of Calanus in the North Sea. ICES CM 1997/T:05 (GLOBEC Theme Session)
(A)

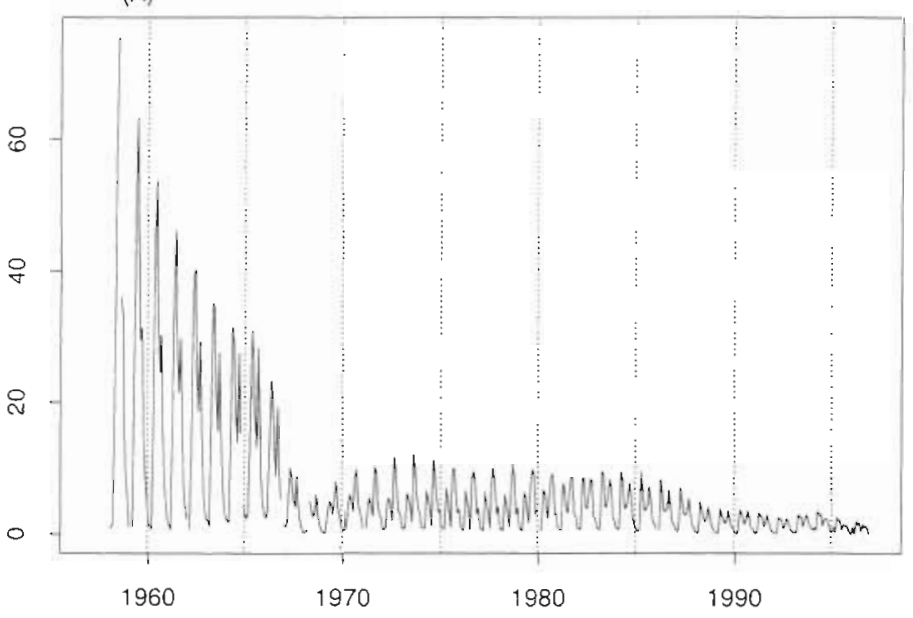

(B)

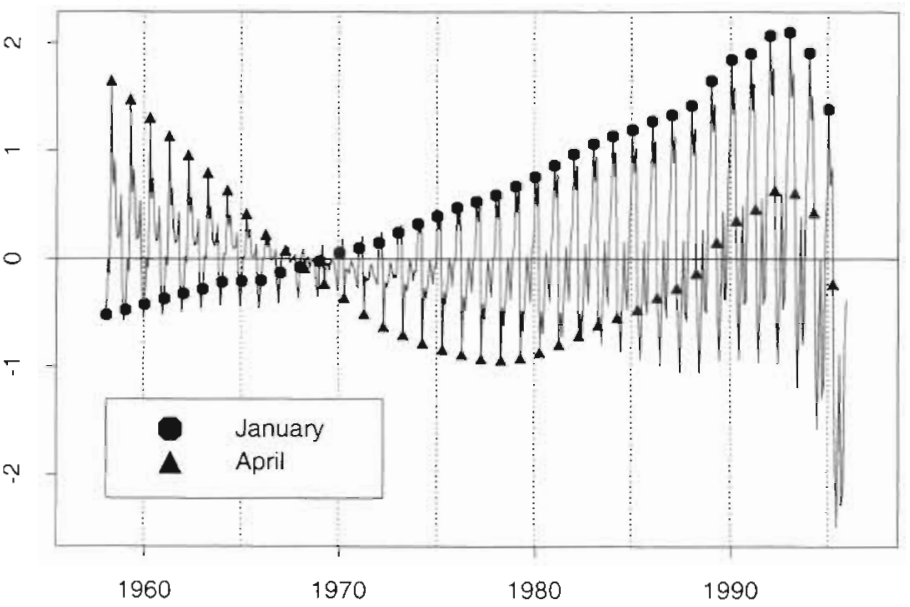

Fig. 2. Long-term and seasonal changes in (A) Calanus finmarchicus abundance in the Fair Isle region $\left(57^{\circ}\right.$ to $61^{\circ} \mathrm{N}, 4^{\circ} \mathrm{W}$ to $\left.0^{\circ}\right)$ and (B) the North Atlantic Oscillation index

Hirche HJ (1996) The reproductive biology of the marine copepod Calanus finmarchicus: a review. Ophelia 44: $129-143$

Hirst AG, Batten SD (1998) Long-term changes in the diel vertical migration behaviour of Calanus finmarchicus in the North Sea are unrelated to fish predation. Mar Ecol Prog Ser 171:307-310

Hurrel JW (1995) Decadal trends in the North Atlantic Oscillation, regional temperature and precipitation. Science 269:676-679

Hurrel JW (1996) Influence of variations in extratropical wintertime teleconnections on Northern Hemisphere temperatures. Geophys Res Lett 23:665-668

Hurrel JW, VanLoon H (1997) Decadal variations in climate associated with the North Atlantic Oscillation. Clim Change 36:301-326

Jones PD, Jonsson T, Wheeler D (1997) Extension to the North Atlantic Oscillation using early instrumental pressure observations from Gibraltar and south-west Iceland. Int J Climatol 17:1433-1450

Warner AJ, Hays GC (1994) Sampling by the Continuous Plankton Recorder Survey. Prog Oceanogr 34:237-256 